\title{
COMPORTAMENTO GEOQUÍMICO DE ÍONS DE METAIS PESADOS (PB, CU, CR E NI) EM ATERROS SANITÁRIOS - SIMULAÇÕES DE CÉLULAS DE LIXO EM COLUNAS EXPERIMENTAIS
}

\author{
SIBELE EZAKI ${ }^{1}$ \& RAPHAEL HYPOLITO ${ }^{2}$
}

\begin{abstract}
The aim of this research is the heavy metals $(\mathrm{Pb}, \mathrm{Cu}, \mathrm{Cr}, \mathrm{Ni})$ behavior associated with a soil/waste/leachate system of two sanitary landfills in the São Paulo Metropolitam Region, São Paulo State. The investigation of the conditions that have influence on metals release, migration and fixation and their interaction with other materials or substances (leachate and solid waste, cover soil) was conducted in two parts. In the first part, the ionic distribution of metals in landfill cells was carried out with soil and leachate sampling and characterisation. The second part consisted of cell simulations with reproduction of chemical and physicchemical processes that occur in a landfill, emphasising heavy metals fixation and mobility mechanisms.
\end{abstract}

Keywords: Heavy Metals; Sanitary Landfill; Leachate; Cover Soil

Resumo Este trabalho trata do comportamento de metais pesados - $\mathrm{Pb}, \mathrm{Cu}, \mathrm{Cr}, \mathrm{Ni}$ - no sistema solo/lixo/chorume de dois aterros sanitários da Região Metropolitana de São Paulo-SP. A investigação das condições que influem nos mecanismos de liberação, transporte e fixação dos metais e sua interação com outros materiais (resíduos líquidos e sólidos, solo de cobertura) no interior do aterro foi realizada em duas etapas. A primeira consistiu no estudo da distribuição dos íons de metais nas células de lixo em aterros, através da caracterização de amostras de chorume e de solo de cobertura (antes e após interação com lixo e chorume). A segunda parte tratou dos mecanismos de fixação e mobilidade dos metais em colunas experimentais com simulação dos processos que ocorrem em células sanitárias.

Palavras-Chave: Metais Pesados; Aterro Sanitário; Chorume, Solo de Cobertura

INTRODUÇÃO Os aterros sanitários, por atenderem normas de proteção ambiental, são considerados um dos métodos mais adequados de disposição final de resíduos sólidos urbanos. Não deixam, contudo, de se constituir numa forma de armazenamento de resíduos no solo e, portanto, uma preocupação quanto a possibilidade de liberação ao meio ambiente de substâncias perigosas presentes no lixo.

Dentre estas substâncias destacam-se os metais pesados provenientes de inúmeras fontes como pilhas, baterias, lâmpadas, utensílios domésticos, materiais eletro-eletrônicos, embalagem de tinta, em resíduos domiciliares. Outras fontes são o lodo de tratamento de esgotos e resíduos industriais classes II e III (ABNT 2004), que podem ser juntamente descartados.

Raros ou inexistentes são os trabalhos de caracterização sistemática dos resíduos e de determinação do efetivo conteúdo de metais presentes no lixo, podendo ser citado o trabalho executado pela LIMPURB (2003) no Município de São Paulo, que foi adotado como referência neste estudo.

Uma vez os resíduos dispostos não se tem mais controle da distribuição de substâncias no interior do aterro; desta forma, a proteção e o controle ambiental dependerão da eficiência da construção e operação do aterro que deve seguir normas técnicas regulamentadas, como por exemplo da Associação Brasileira de Normas Técnicas, NBR 8419/92 (ABNT, 1992) e NBR 13896/97 (ABNT 1997). Entre as exigências estão incluídas impermeabilização da base do aterro, cobertura diária de resíduo com solo, sistema de coleta de chorume e gases etc. (Tchobanoglous et al.1993, Boulton 1995).

Nos aterros, uma das técnicas de armazenamento do lixo é realizada através de células sanitárias, nas quais o lixo é descarregado próximo ao talude e compactado por tratores formando rampa; em seguida, também com trator, é assentada uma camada de solo com 20 a $50 \mathrm{~cm}$ de espessura. Ao final de cada dia, tem-se um conjunto lixo/solo que se constitui numa célula.

O solo de cobertura desempenha função de minimizar a entrada de água de chuva no aterro, evitar escapes de gases e líquidos, evitar a presença de vetores de doença, impedir espalhamento de materiais leves, e de especial interesse neste trabalho, reter substâncias poluentes (Bruner \& Keller 1977, Christensen et al. 1992).

Este trabalho teve como objetivo determinar os mecanismos de mobilidade e fixação dos agentes poluidores em aterros. Estudou-se o comportamento dos íons $\mathrm{Pb}, \mathrm{Cu}, \mathrm{Cr}$ e $\mathrm{Ni}$ associados ao sistema solo de cobertura/lixo/chorume de dois aterros sanitários da Região Metropolitana de São Paulo, SP.

O Aterro I situa-se na divisa entre os Municípios de Caieiras e São Paulo e o Aterro II, na região do Grande $A B C$, entre os municípios de Santo André, Mauá e Ribeirão Pires. O primeiro recebe resíduos domiciliares, lodos de esgotos, resíduos industriais e é operado por empresas contratadas pela Prefeitura Municipal há mais de 30 anos. O segundo recebe basicamente resíduos domiciliares e é operado por empresa privada há cerca de 15 anos.

As condições que influem nos mecanismos de liberação, transporte e fixação de metais nos aterros foram estudadas através de experimentos em colunas com reproduções de células sanitárias, e os resultados foram correlacionados com dados coletados nos aterros.

METODOLOGIA. Os estudos foram conduzidos fundamentalmente em duas etapas que consistiram na coleta e caracterização de solos e chorumes dos aterros e na realização dos experimentos com simulações de sistemas solo/lixo/água/metais pesados utilizando solos dos Aterros I e II.

Amostras dos Aterros I e II - Coleta e Preparação Próxi-

\footnotetext{
${ }^{1}$ Instituto Geológico/SMA-SP - Av. Miguel Stéfano, 3900, Água Funda CEP:04301-903 São Paulo/SP (E-mail: sibezaki@igsma.sp.gov.br); USP/Instituto de Geociências (E-mail: sibezaki@usp.br)

${ }^{2}$ Universidade de São Paulo, Instituto de Geociências - Rua do Lago, 562, Cidade Universitária CEP: 05508-080 São Paulo/SP (E-mail: raphael.hypolito@br2001.com.br)
} 
mo aos aterros coletaram-se, ao longo de perfis, subamostras de solo não impactado que foram tomadas como referência (background) e reunidas, formando amostras compostas. Em algumas camadas dos aterros amostras de solo superficiais e do interior das células, impactadas pelo contato com lixo e chorume, foram coletadas com auxílio de pá, trado e de retro-escavadeira totalizando, respectivamente, 7 e 9 amostras dos Aterros I e II.

Para caracterização textural, mineralógica (DRX - SIEMENS-D5000) química (FRX - PW2400 / Phillips), determinação da capacidade de troca catiônica e de pH (RAIJ et al. 1987) foram utilizadas frações menores que $2 \mathrm{~mm}$.

As determinações dos metais pesados associados aos solos foram realizadas por espectrofotometria de absorção atômica (AA700BC/CG), em soluções obtidas por extrações totais $\left(\mathrm{HNO}_{3} 8 \mathrm{M}\right)$ e seletivas (Marques 2003).

Amostras de chorume bruto foram coletadas na entrada dos tanques de armazenamento dos aterros, armazenadas em frascos de polietileno e preservadas a $4^{\circ} \mathrm{C}$. Em campo, foram medidos os valores de potencial de óxido-redução (Eh), $\mathrm{pH}$, temperatura e condutividade elétrica (CE).

Para análises químicas, o chorume foi dividido em duas alíquotas: uma analisada após acidulação com $\mathrm{HNO}_{3}$, e outra, objetivando determinar os teores dos íons metálicos associados à matéria orgânica, tratada previamente com $\mathrm{HNO}_{3} / \mathrm{H}_{2} \mathrm{O}_{2}$.

EXPERIMENTOS A etapa experimental consistiu na reprodução das condições dos aterros com controle rigoroso das características dos chorumes gerados e das fases de decomposição de resíduos orgânicos. Os parâmetros experimentais foram, sempre que possível, também acompanhados in situ nos Aterros Sanitários I e II.

Foram realizados três experimentos em colunas, cujas características construtivas encontram-se descritas a seguir.

Nos dois primeiros foi utilizado solo referência do Aterro I e no terceiro, solo do Aterro II.

Montagem dos dispositivos: experimento 1 - colunas A e B Para a montagem das colunas representativas de células do Aterro I foram utilizados tubos de $\operatorname{PVC}(\varnothing=15 \mathrm{~cm} ; \mathrm{h}=50 \mathrm{~cm})$, vedados nas extremidades com tampões fixos na base e móveis na entrada (Figura 1).

No interior de cada coluna, simulando poços, na porção central, foram fixados tubos também de PVC $(\varnothing=4 \mathrm{~cm} ; \mathrm{h}=50 \mathrm{~cm})$, vazados com furos de $2 \mathrm{~mm}$ de diâmetro (filtros). Estes tubos

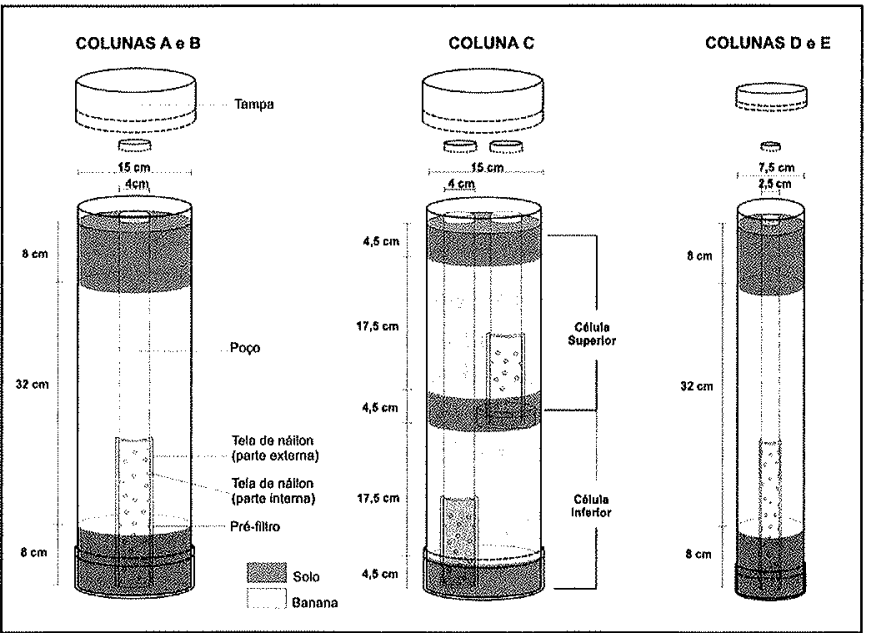

Figura 1. Esquema construtivo das colunas experimentais $A$, $B, C, D e E$. foram revestidos com tela de náilon ( $\# 122 \mu \mathrm{m})$, e envolvidos com areia quartzosa média a grossa para atuar como pré-filtro. Outro revestimento com tela de nylon envolveu este conjunto pará que não ocorresse mistura de partículas de areia com o lixo orgânico. Este tubo permitiu acompanhamento de parâmetros experimentais como $\mathrm{pH}$, Eh, temperatura, condutividade elétrica da fase líquida gerada no processo.

Com o intuito de obter o sistema protegido de ação da luz e manter constante a temperatura no interior da coluna, evitando proliferação de insetos, manteve-se isolada em caixa térmica de isopor.

As células de lixo do Aterro I apresentam em média a proporção de 8:1 em relação às espessuras das camadas de lixo e de solo de cobertura. Nos experimentos, para acelerar o processo de decomposição da matéria orgânica, esta proporção foi reduzida para 4:1 (lixo:solo).

Sobre a camada de solo da base assentaram-se, sem compactar, pedaços centimétricos de banana que, por sua vez, foram cobertos com nova camada de solo.

A Coluna A refere-se ao experimento-referência, no qual utilizou-se solo natural, banana e água destilada.

A Coluna B apresenta as mesmas características da Coluna $\mathrm{A}$, com adição periódica de soluções contendo concentrações conhecidas dos íons de metais pesados $\mathrm{Pb}, \mathrm{Cr}, \mathrm{Cu}$ e $\mathrm{Ni}$.

Experimento 2 - Coluna C (células C-Superior e C-Inferior) Este experimento teve como objetivo simular duas células sanitárias utilizando também solo do Aterro I, em tubo de PVC com características semelhantes ao Experimento 1. No interior desta coluna, duas camadas de lixo (bananas) foram dispostas e intercaladas a camadas de solo, respeitando as proporções 4:1 (Lixo:solo).

A coluna continha duas células, C-Inferior, com 1 poço para coleta de chorume de ambas as células e C-Superior com as mesmas características da célula $\mathrm{A}$ também com 1 poço para coleta da fase líquida (Figura 1). Na base da camada intermediária de solo, foi adaptado uma tampa (cap) de $\varnothing=10 \mathrm{~cm}$ que possibilitou o armazenamento de chorume da célula C-Superior e sua coleta.

$\mathrm{Na}$ Coluna $\mathrm{C}$ também foram percoladas soluções com concentrações conhecidas dos metais pesados de interesse.

Experimento 3 - Colunas D E $\mathbf{E} \quad$ O estudo do comportamento dos componentes do lixo associados ao solo do Aterro II foi efetuado de modo semelhante ao do Aterro I. Procurou-se, entretanto, acelerar o processo utilizando colunas de menores dimensões e menores quantidades de solo/lixo.

Utilizaram-se colunas de PVC com $50 \mathrm{~cm}$ de altura e $7,5 \mathrm{~cm}$ de diâmetro e como poço utilizaram-se tubos de $2,54 \mathrm{~cm}$ de diâmetro, tendo na base furos de $2 \mathrm{~mm}$ de diâmetro, envoltos com malha de nylon e, como pré-filtro, areia média a grossa tratada.

Os materiais utilizados nas colunas, solo referência e banana, foram dispostos e assentados da mesma forma que nos experimentos anteriores. As espessuras das camadas foram as mesmas do Experimento 1.

A Coluna D refere-se ao experimento-referência e na Coluna $\mathrm{E}$ foram adicionadas as mesmas soluções contendo concentrações conhecidas dos íons $\mathrm{Pb}, \mathrm{Cr}, \mathrm{Cu}$ e $\mathrm{Ni}$.

PROCEDIMENTOS A geração de percolado foi obtida pela adição controlada de água (branco) e soluções de íons metálicos de interesse. Para se conseguir a fase líquida ausente de ar atmosférico, borbulhou-se gás nitrogênio nas soluções antes de serem adicionadas às colunas.

Nas colunas $\mathbf{A}$ e $\mathbf{D}$ adicionou-se água destilada e as soluções inseridas nas demais colunas $(\mathbf{B}, \mathbf{C}$ e $\mathbf{E}$ ) continham misturas de 
íons de $\mathrm{Pb}, \mathrm{Ni}, \mathrm{Cr}$ e $\mathrm{Cr}$ ( $1 \mathrm{ppm}$ cada); foram medidos os valores de $\mathrm{pH}$ de todas as soluções.

As colunas foram mantidas saturadas em solução aquosa, assegurando-se a decomposição anaeróbia da matéria orgânica.

Durante o processo experimental as fases de decomposição microbiológica, foram acompanhadas através de leituras de parâmetros indicativos como temperatura, $\mathrm{pH}$ (Potenciômetro DIGIMED), potencial de óxi-redução (Potenciômetro DIGIMED) e condutividade elétrica (Condutivímetro WTW). O acompanhamento também foi efetuado com leituras de $\mathrm{Na}^{+}$e $\mathrm{K}^{+}$por Fotometria de Chama (B262/Micronal).

As amostras dos chorumes gerados foram retiradas com auxílio de pipetas volumétricas para leitura imediata dos parâmetros acima mencionados. Foram lidas as temperaturas ambiente e no interior das colunas. A umidade relativa no interior das colunas manteve-se, durante todo o experimento, próximo a $100 \%$.

Para acompanhamento da concentração dos f́ons $\mathrm{Pb}, \mathrm{Cr}, \mathrm{Cu}$ e $\mathrm{Ni}$ as amostras foram previamente tratadas com $\mathrm{H}_{2} \mathrm{O}_{2}$ para eliminação da matéria orgânica, procedendo-se a leitura das concentrações de metais.

As coletas de chorume foram realizadas, inicialmente, duas vezes por semana, após $12 \mathrm{~h}$ da adição de água/solução nas colunas ( $200 \mathrm{~mL}$ em A,B e C; $100 \mathrm{~mL}$ em D e E). Constatando-se pequenas variações dos parâmetros experimentais, as coletas passaram a ser apenas semanais.

Os experimentos 1 e 2 foram mantidos em funcionamento por 12 meses e o terceiro por 9 meses.

\section{RESULTADOS E DISCUSSÕES}

Caracterização dos Solos dos Aterros O solo (referência) do Aterro I apresenta textura fina, argilosa a franco argilosa, conforme classificação do Departamento de Agricultura dos Estados Unidos. A fração argilosa é composta essencialmente de caulinita, muscovita e illita. A capacidade de troca cationica (CTC) deste solo é baixa com $13,7 \mathrm{mmol}_{\mathrm{c}} \mathrm{kg}^{-1}$.

O solo do Aterro II é mais arenoso, variando de franco argilo-arenoso a franco (partículas de fração areia, silte e argila em igual proporção), apresenta mineralogia semelhante ao Aterro I contendo, no entanto, vermiculita como componente a mais, responsável pela maior CTC $\left(38,8 \mathrm{mmol}_{\mathrm{c}} \mathrm{kg}^{-1}\right)$.

Os valores de $\mathrm{pH}$ dos solos tomados como referência variam de 4 a 5 , enquanto os impactados em ambos os aterros, mostram valores em torno de 7, indicando que ocorreu alteração das características do solo. Quanto ao $\Delta \mathrm{pH}$ constatou-se que a maioria das amostras apresentou valores positivos indicando aptidão à adsorção de íons positivos.

As análises químicas por fluorescência de raios $X$ (FRX) para os metais pesados nos solos revelam, na maior parte dos casos, enriquecimento nas amostras impactadas em relação ao solo de referência (branco). Os resultados, em alguns casos, ultrapassam os valores orientadores de ALERTA estabelecidos pela CETESB, em destaque na Tabela 1 .

No Aterro I os teores são mais elevados devido o descarte de resíduos industriais e de lodos de esgoto, enquanto no Aterro II os solos não apresentaram enriquecimento significativo. O cromo, nas amostras tomadas como referência, em ambos os aterros, apresentou-se como um contaminante originado da rocha mãe.

Extrações As extrações totais e seletivas mostraram elevadas concentrações de metais pesados adsorvidos às partículas sólidas (Tabela 2) e baixa disponibilidade iônica intersticialmente (Tabela 3).

Chorume Os chorume dos aterros apresentaram características muito semelhantes: em ambos tem-se $\mathrm{pH}$ alcalino (média 8,3 ), potencial de óxi-redução bastante redutor (valor médio $200 \mathrm{mV}$ ) e elevada condutividade elétrica (média $30 \mathrm{mS} \mathrm{cm}^{-1}$ ).

Todas as amostras, como era de se esperar, apresentaram baixos teores de metais pesados. Os íons metálicos dos chorumes encontram-se parcialmente em solução (filtrada) e em parte fixados às partículas sólidas tanto é que após tratamento com $\mathrm{HNO}_{3} / \mathrm{H}_{2} \mathrm{O}_{2}$ e dissolução total, observou-se elevação de seus teores (Tabela 4).

Resultados Experimentais Os chorumes gerados em todas as colunas apresentaram comportamento muito semelhantes quanto aos parâmetros analíticos. Foram selecionados, por este motivo, apenas os diagramas mais representativos da evolução dos processos obtidos experimentalmente (Figura 2).

A partir dos resultados foram estabelecidas quatro fases de decomposição da matéria orgânica: aeróbia, aeróbia/anaeróbia, anaeróbia e metanogênica.

A fase aeróbia teve curta duração, cerca de uma semana, com queda de $\mathrm{pH}$, devido a formação de ácidos orgânicos solúveis e de $\mathrm{CO}_{2}$. Ocorreu solubilização dos materiais e elevação dos teores de $\mathrm{Na}^{+}$e K${ }^{+}$e, consequentemente, da CE. Esta fase inicial coincide com os resultados de Stantforth et al. (1979 apud Lima 1988) e Pohland \& Harper (1985).

Obteve-se, a seguir, uma fase intermediária, aqui denominada aeróbia/anaeróbia, constatada pelo acréscimo de $\mathrm{K}^{+}$, escolhido como referência por ser o íon mais móvel no tipo de material utilizado nos experimentos e pela constância de $\mathrm{pH}$ e início de sua elevação. A gradativa diminuição de $\mathrm{CE}$ e de $\mathrm{Na}^{+}$e $\mathrm{K}^{+}$em solução representam lixiviação contínua dos materiais das colunas constatada até o final dos experimentos.

$\mathrm{Na}$ fase anaeróbia, as transformações químicas no lixo propiciaram elevação progressiva do $\mathrm{pH}$ tendendo à alcalinidade como relatados por Schalch $(1984,1992)$, Bozkurt et al. (2000) e Kjeldsen et al. (2002).

O potencial de oxi-redução, que oscilou por longo tempo,

Tabela 1. Conteúdo de metais pesados nos solos dos Aterros I e II.

\begin{tabular}{|c|c|c|c|c|c|c|c|c|c|c|c|}
\hline \multirow[t]{2}{*}{$\begin{array}{c}\text { Metal } \\
\left(\mathrm{mg} \mathrm{kg}^{-1}\right)\end{array}$} & \multirow{2}{*}{$\begin{array}{l}\text { Limite de } \\
\text { Deteç̧ão } \\
\left(\mathrm{mg} \mathrm{kg}^{-1}\right)\end{array}$} & \multicolumn{4}{|c|}{ Aterro I } & \multicolumn{4}{|c|}{ Aterro II } & \multicolumn{2}{|c|}{$\begin{array}{l}\text { Valores Orientadores } \\
\text { para Solos (CETESB } \\
\text { 2001). }\end{array}$} \\
\hline & & Média & Máx. & Min. & Branco & Média & Máx. & Mín. & Branco & Referência & Alerta $^{(*)}$ \\
\hline $\mathbf{P b}^{2+}$ & 5 & 73 & 242 & 17 & 22 & 38 & 97 & 16 & 24 & 17 & 100 \\
\hline $\mathrm{Cu}^{2+}$ & 2 & 62 & 129 & 24 & 23 & 18 & 27 & 9 & 24 & 35 & 60 \\
\hline $\mathrm{Cr}_{\text {total }}$ & 2 & 97 & 114 & 83 & 107 & 39 & 73 & 16 & 80 & 40 & 75 \\
\hline $\mathrm{Ni}^{2+}$ & 2 & 48 & 59 & 39 & 11 & 36 & 59 & 12 & 12 & 13 & 30 \\
\hline
\end{tabular}


Tabela 2. Resultado das extrações seletivas de metais de solo em HNO3 (8M) dos Aterros I e II.

\begin{tabular}{|c|c|c|c|c|c|c|c|c|c|}
\hline \multirow{2}{*}{$\begin{array}{c}\text { Metal } \\
\left(\mathrm{mg} \mathrm{dm}^{-3}\right)\end{array}$} & \multirow{2}{*}{$\begin{array}{l}\text { Limite de } \\
\text { Detecção } \\
\left(\mathrm{mg} \mathrm{dm}^{-3}\right)\end{array}$} & \multicolumn{4}{|c|}{ Aterro I } & \multicolumn{4}{|c|}{ Aterro II } \\
\hline & & Média & Máx. & Min. & Branco & Média & Máx. & Mín. & Branco \\
\hline $\mathbf{P b}^{2+}$ & 0,05 & 30,60 & 89,50 & 9,20 & 2,80 & 19,60 & 44,00 & 3,10 & 3,90 \\
\hline $\mathrm{Cu}^{2+}$ & 0,025 & 12,20 & 25,40 & 4,30 & 0,40 & 7,00 & 26,50 & 1,70 & 0,40 \\
\hline $\mathrm{Cr}_{\text {total }}$ & 0,02 & 2,90 & 6,90 & 0,90 & n.d. & 4,20 & 10,10 & 1,00 & 0,40 \\
\hline $\mathrm{Ni}^{2+}$ & 0,04 & 6,90 & 12,50 & 2,10 & 0,40 & 3,60 & 5,20 & 1,50 & 0,30 \\
\hline
\end{tabular}

n.d.: Não detectado

Tabela 3. Resultado das extraçôes seletivas com água de metais de solo em água dos Aterros I e II.

\begin{tabular}{|c|c|c|c|c|c|c|c|c|c|}
\hline \multirow{2}{*}{$\underset{\left(\mathrm{mg} \mathrm{dm}^{-3}\right)}{\text { Metal }}$} & \multirow{2}{*}{$\begin{array}{l}\text { Limite de } \\
\text { Detecção } \\
\left(\mathrm{mg} \mathrm{dm}^{-3}\right)\end{array}$} & \multicolumn{4}{|c|}{ Aterro I } & \multicolumn{4}{|c|}{ Aterro II } \\
\hline & & Média & Máx. & Mín. & Branco & Média & Máx. & Min. & Branco \\
\hline $\mathrm{Pb}^{2+}$ & 0,05 & n.d. & n.d. & n.d. & n.d. & n.d. & n.d. & n.d. & n.d. \\
\hline $\mathrm{Cu}^{2+}$ & 0,025 & 0,10 & 0,40 & n.d. & 0,10 & 0,15 & 0,50 & n.d. & 0,20 \\
\hline $\mathrm{Cr}_{\text {total }}$ & 0,02 & 0,03 & 0,10 & n.d. & n.d. & 0,01 & 0,10 & n.d. & n.d. \\
\hline $\mathrm{Ni}^{2+}$ & 0,04 & 0,08 & 0,30 & n.d. & n.d. & 0,04 & 0,40 & n.d. & n.d. \\
\hline
\end{tabular}

Tabela 4. Valores médios de teores de metais pesados no chorume dos Aterros I e II

\begin{tabular}{|c|c|c|c|c|c|c|}
\hline \multirow[b]{2}{*}{$\begin{array}{c}\text { Metal } \\
\left(\mathrm{mg} \mathrm{dm}^{-3}\right)\end{array}$} & \multirow{2}{*}{$\begin{array}{l}\text { Limite de } \\
\text { Detecção } \\
\left(\mathrm{mg} \mathrm{dm}^{-3}\right)\end{array}$} & \multirow[b]{2}{*}{ VMP ${ }^{(*)}$} & \multicolumn{2}{|c|}{ Aterro I } & \multicolumn{2}{|c|}{ Aterro II } \\
\hline & & & $\begin{array}{l}\text { Chorume } \\
\text { Filtrado }\end{array}$ & $\begin{array}{c}\text { Tratado } \\
\left(\mathrm{H}_{2} \mathrm{O}_{2} / \mathrm{HNO}_{3}\right)\end{array}$ & $\begin{array}{l}\text { Chorume } \\
\text { Filtrado }\end{array}$ & $\begin{array}{c}\text { Tratado } \\
\left(\mathrm{H}_{2} \mathrm{O}_{2} / \mathrm{HNO}_{3}\right)\end{array}$ \\
\hline $\mathbf{P b}^{2+}$ & 0,05 & 1,50 & 0,10 & 0,14 & 0,03 & 0,61 \\
\hline $\mathrm{Cu}^{2+}$ & 0,025 & 1,50 & 0,05 & 0,15 & 0,06 & 0,07 \\
\hline $\mathrm{Cr}_{\text {total }}$ & 0,02 & 5,00 & 0,30 & 0,47 & 0,31 & 0,48 \\
\hline $\mathrm{Ni}^{2+}$ & 0,04 & 2,00 & 0,30 & 0,39 & 0,27 & 0,57 \\
\hline
\end{tabular}

tornou-se cada vez mais redutor, característico da fase anaeróbia metanogênica que somente foi atingida no experimento com as colunas D e E em função de suas menores dimensões que permitiram a aceleração dos processos de decomposição.

Ao se analisar a evolução do experimento na Coluna $C$, verifica-se que as tendências dos parâmetros experimentais assemelham-se às demais colunas, embora tenham ocorrido particularidades nas células Superior e Inferior (Figura 3).

$\mathrm{Na}$ célula Superior, dada a menor quantidade de material utilizado, ocorreu aceleração dos processos de decomposição microbiológica semelhante às células $\mathrm{D}$ e $\mathrm{E}$ do Experimento 3. $\mathrm{O}$ chorume apresentou acentuado declínio de $\mathrm{CE}$ e de $\mathrm{K}^{+} \mathrm{e}$ $\mathrm{Na}^{+}$, além da elevação do $\mathrm{pH}$ que chegou a 7,0. Outro aspecto a ser considerado é a interferência desta célula na célula Inferior, quanto à percolação de chorume e conseqüente transferência de massa que intensificaram os fenômenos e ampliaram a duração da fase de transição (Figura 3).

Comportamento dos Metais Pesados Durante os experimentos constatou-se adsorção contínua de íons metálicos sem ocupar, no entanto, todos os sítios de adsorção (Figura 4).
Os resultados das colunas impactadas (B e E), em relação às respectivas colunas referenciais $(\mathrm{A} e \mathrm{D})$, indicaram pouca ou nenhuma influência da adição dos íons metálicos - $\mathrm{Pb}, \mathrm{Cr}$, $\mathrm{Cr}$ e Ni, devido aos baixos teores adicionados (1ppm), fato este comprovado pelos valores de $\mathrm{pH}, \mathrm{Na}, \mathrm{K}$ e CE que mantiveram comportamentos semelhantes nas colunas. Desta forma, foram selecionados apenas os diagramas de concentração de metais pesados mais representativos (Figura 4).

A disponibilidade iônica está estreitamente relacionada ao pH do meio; nas fases iniciais, com a solubilização dos materiais decorrente da diminuição do pH e aumento da força iônica, houve deslocamento dos metais adsorvidos, que ocorreram na forma iônica livre.

Com a elevação de $\mathrm{pH}$, a partir de $5,0, \mathrm{o} \mathrm{Pb}$ e o $\mathrm{Cu}$ foram retidos no solo por adsorção e precipitação nas formas óxi-hidróxida e carbonática, sendo o $\mathrm{CO}_{2}$ derivado da decomposição na fase anaeróbia. As concentrações destes íons, portanto, foram diminuídas no chorume.

$\mathrm{O}$ níquel manteve-se em solução na forma aquocomplexa $\left(\left[\mathrm{Ni}\left(\mathrm{H}_{2} \mathrm{O}\right)_{6}\right]^{2+}\right)$, e não sofreu grande variação em função do $\mathrm{pH}$ e Eh e sua fixação deveu-se essencialmente aos fenômenos de 


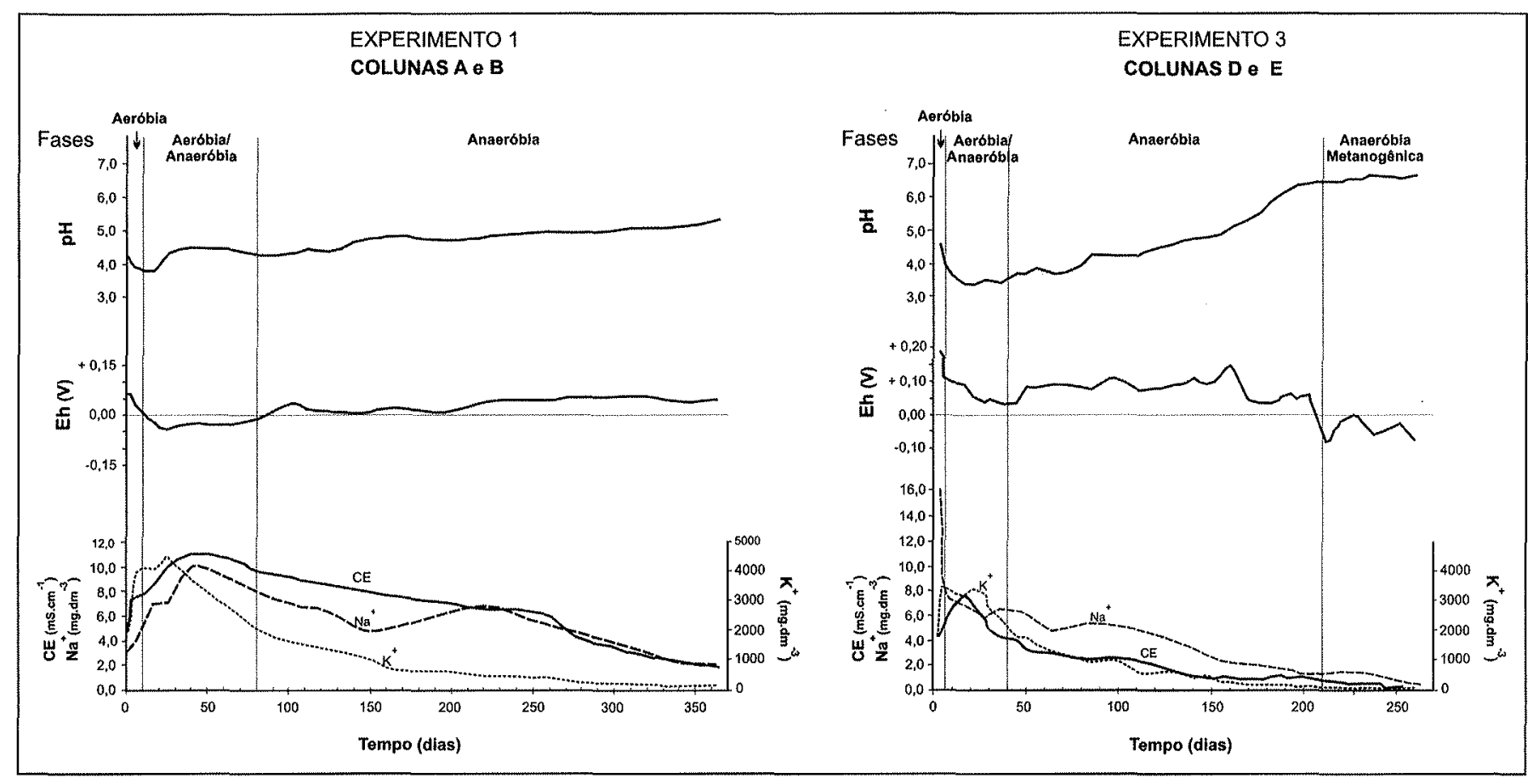

Figura 2. Evolução dos parâmetros experimentais pH, Eh, CE, Na e K, nos chorumes dos Experimentos 1 e 3.

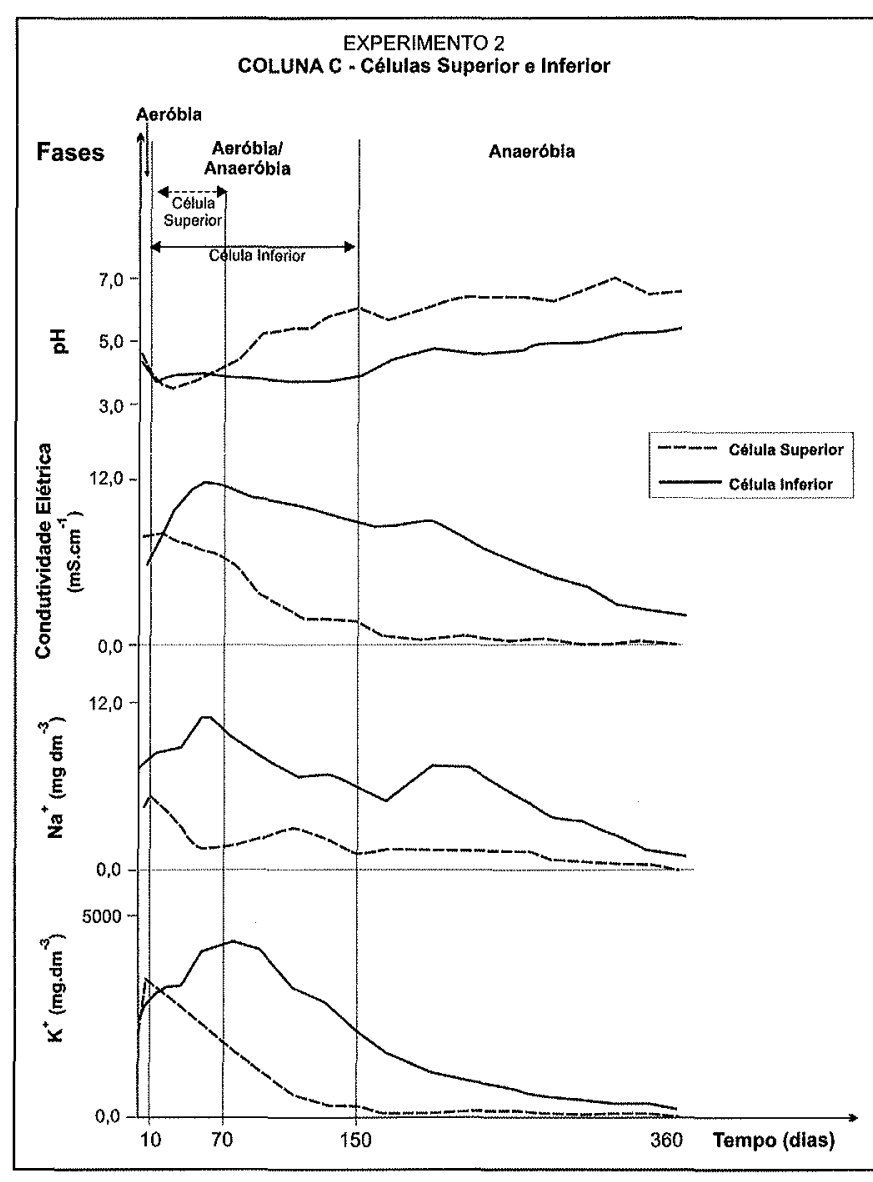

Figura 3. Evolução das características do chorume nas células superior e inferior da Coluna $C$-Experimentol.

adsorção.

Dentre os metais estudados, o cromo apresentou compor-

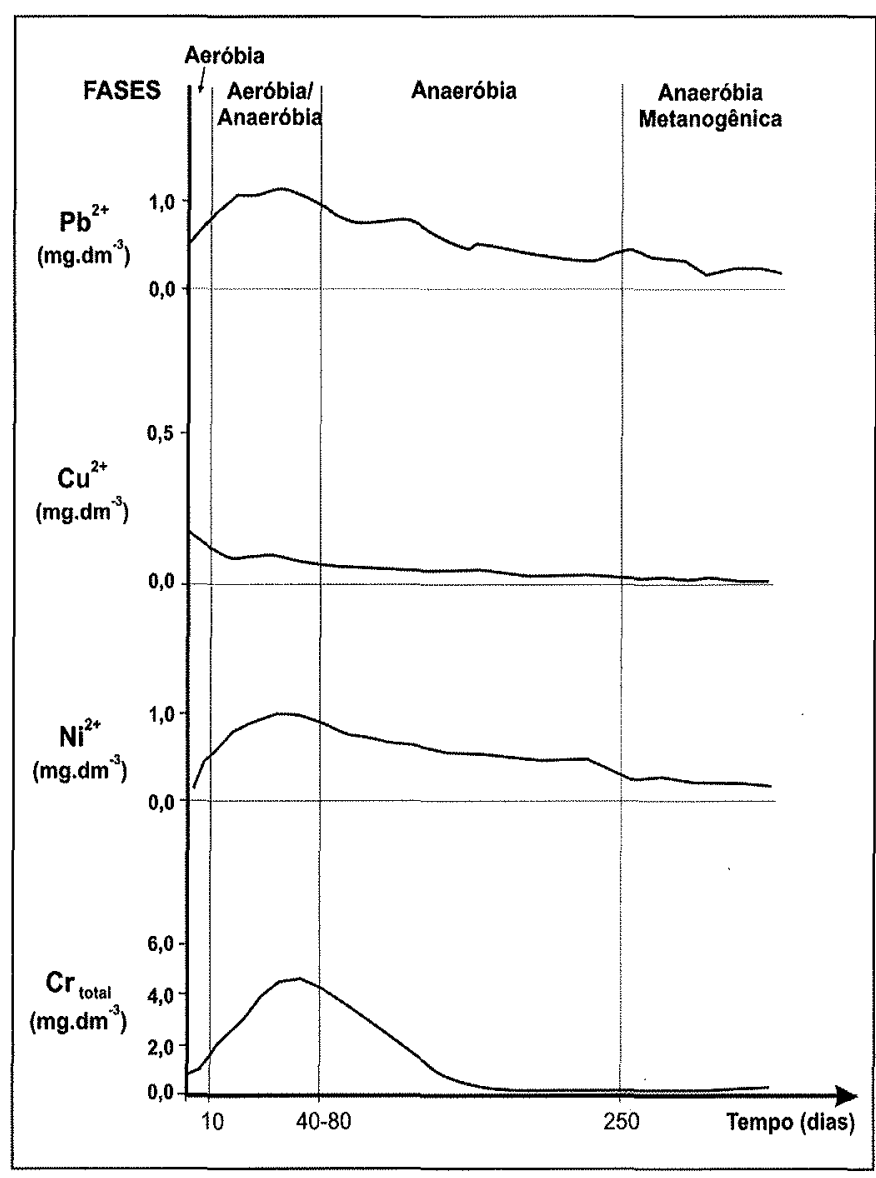

Figura 4. Concentrações de metais pesados ( $\mathrm{Pb}, \mathrm{Cu}, \mathrm{Cr}$ e $\mathrm{Ni}$ ) no chorume dos experimentos.

tamento diferenciado por sofrer maior influência das variações de $\mathrm{pH}$ e, principalmente, de Eh. Assim, com o predomínio de 


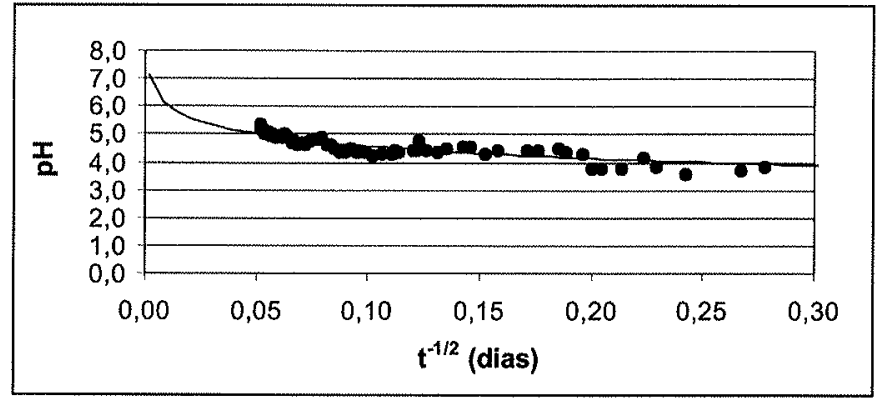

Figura 5. Tendência do pH nas células experimentais.
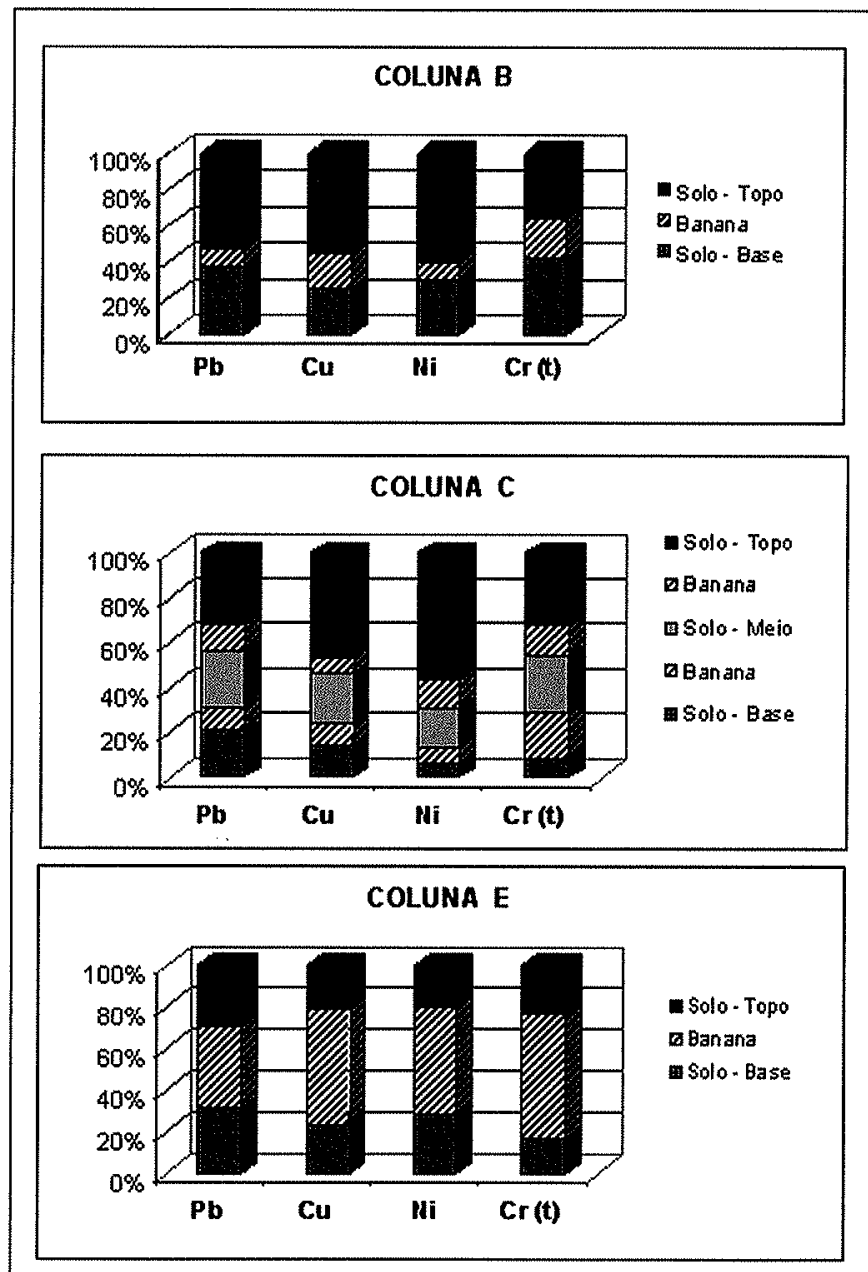

Figura 6. Resultados das extrações nitricas de metais pesados das Colunas $B$ e $C$ (solo do Aterro I) e $E$ (solo do Aterro II).

ambiente redutor nas células, associado às condições de $\mathrm{pH}$ ácido $(\mathrm{pH}<5,0)$, a disponibilidade do cromo ocorreu como ín complexo dissolvido $\left([\mathrm{CrOH}]^{2+}\right)$. Na fase anaeróbia metanogênica, com a tendência de aumento de $\mathrm{pH}$, sua disponibilidade diminuiu, passando a ocorrer em sua forma mais estável como $\mathrm{Cr}(\mathrm{OH})$

$\mathrm{O}$ pH de equilíbrio dos processos de decomposição do lixo, extrapolado para tempo infinito, foi determinado pela projeção de $\mathrm{pH}$ em função do inverso da raiz quadrada do tempo, obtendo-se valor ao redor de $\mathbf{8 , 0}$ (Figura 5), semelhante aos chorumes dos aterros, indicando que na fase de estabilização do aterro a tendência é de fixação e retenção dos metais pesados.
Finalização dos Experimentos No final dos experimentos o chorume remanescente das colunas foi esgotado e as colunas foram abertas para exame dos materiais de cada compartimento. Para determinação dos teores de metais pesados estes materiais foram submetidos à extração nítrica e analisados quimicamente.

Tanto na coluna $\mathrm{B}$ como na coluna $\mathrm{C}$, com exceção do cromo, contatou-se maior adsorção de metais pesados no topo (Figura 6). A retenção de metais na matéria orgânica ocorreu com menor intensidade devido à formação de íons complexos solúveis que imprimiu maior mobilidade iônica. A adição intermitente de eletrólitos e a presença de matéria orgânica impediram que os sítios de adsorção fossem completamente ocupados.

$\mathrm{Na}$ Coluna E, em função das características do solo do Aterro II, o comportamento iônico foi distinto: sua textura, mais arenosa, favoreceu maior velocidade de fluxo no processo de lixiviação, menor tempo de residência do sistema íon/solo e, conseqüentemente, menor adsorção. $\mathrm{O}$ acúmulo dos metais na camada de matéria orgânica (representada pela banana) deve-se ao $\mathrm{pH}$ mais elevado que propiciou precipitações na forma óxihidróxida.

CONCLUSÕES Os experimentos reproduziram com eficácia os fenômenos que ocorrem nos aterros, comprovados pela obtenção das fases de decomposição aeróbia, aeróbia/anaeróbia, anaeróbia e metanogênica.

Constatou-se que o comportamento dos íons de metais pesados presentes no sistema solo/lixo/chorume está relacionado às condições químicas e físico-químicas impostas pelas fases de decomposição do lixo.

Nas fases iniciais, a queda de $\mathrm{pH}$ ocorre devido a presença de ácidos orgânicos complexantes e ao desenvolvimento contínuo de $\mathrm{CO}$, favorecendo o aumento de solubilidade e da força iônica e, por conseguinte, maior disponibilidade de íons de metais pesados. Estas fases demonstram que no início das atividades de um aterro, as características químicas e físico-químicas do chorume devem ser monitoradas, com rigoroso cuidado.

$\mathrm{Na}$ fase anaeróbia, com o consumo de ácidos orgânicos, ocorre elevação do $\mathrm{pH}$ e, consequentemente, decréscimo dos teores de metais disponíveis.

Os dados experimentais permitiram que se determinasse o $\mathrm{pH}$ de equilíbrio dos processos de decomposição nas células com valores em torno de 8,0 , semelhante ao chorume dos aterros estudados, demonstrando que nas fases de estabilização do aterro a tendência é de fixação e retenção dos metais pesados.

Os experimentos permitiram concluir que a retenção iônica no solo do Aterro I ocorreu com maior eficiência, indicando que, embora o solo do Aterro II tenha apresentado maior capacidade de troca catiônica, a composição textural prevalesceu para a retenção de metais pesados.

Como a separação de resíduos perigosos em aterros não é efetuada com a necessária eficácia, recomenda-se às empresas operadoras de aterros, a seleção de solos apropriados especialmente quanto às características texturais, mineralógicas e químicas.

$\mathrm{O}$ estudo experimental do comportamento de metais em solos do interior de aterros possibilitou a compreensão dos mecanismos de mobilidade e fixação de íons e podem se estender aos lixões e às áreas contíguas aos aterros.

AGRADECIMENTOS. Ao Centro de Pesquisa de Águas Subterrâneas-CEPAS/IGc-USP por possibilitar a execução dos experimentos e análises nos Laboratórios de Hirogeoquímica I, II e III e à CAPES pela bolsa de estudo concedida à pósgraduanda. 


\section{Referências}

ABNT-ASSOCIAÇÃO BRASILEIRA DE NORMAS TÉCNICAS. 2004. Resíduos Sólidos - Classificação. NBR-10004. São Paulo: ABNT.

ABNT-ASSOCIAÇÃO BRASILEIRA DE NORMAS TÉCNICAS. 1997. Aterros de resíduos não perigosos - critérios para projetos, implantação e operação. NBR 13896. São Paulo: ABNT.

ABNT-ASSOCIAÇÃO BRASILEIRA DE NORMAS TÉCNICAS. 1992. Apresentação de Projetos de Aterros Sanitários de Resíduos Sólidos Urbanos - Procedimentos. NBR-8419. São Paulo: ABNT.

BOULTON, P. E. N. 1995. The handbook of landfill operations. A practical guide for landfill engineers, owners, and operators. Atascadero, Blue Ridge Services. 534 pp.

BOZKURT S., MORENO L., NERETNIEKS I. 2000. Long-term processes in waste deposits. The Science of the Total Environment, $250: 101-121$

BRUNER D.R., KELLER D.J. 1977. Sanitary Landfill: Design and Operation. Washington, USEPA, 67pp. (Solid Waste Management Series, SW-65ts PB 227 565/9BE).

CETESB-COMPANHIA DE TECNOLOGIA DE SANEAMENTO AMBIENTAL, São Paulo (Estado). 2001. Relatório de estabelecimento de valores orientadores para solos e águas subterrâneas no Estado de São Paulo / Dorothy C.P. Casarini [et al]. São Paulo, CETESB, 2001. (Série Relatórios Ambientais). (Disponível em $<$ http:// cetesb.sp.gov.br $>$ ).

CHRISTENSEN T.H, KJELDSEN P., STEGMANN R. 1992. Effects of Landfill Management Procedures on Landfill Stabilization and Leachate and Gas Quality. In: Christensen T.H., Cossu R., Stegmann R. (Eds.) Landfilling of Waste: Leachate. London, Chapman \& Hall, pp.:119-137.

KJELDSEN P., BARLAZ M.A., ROOKER A.P., BAUN A., LEDINA., CHRISTENSEN T. H. 2002. Present and Long-Term Composition of MSW Landfill Leachate: a Review. Critical Reviews in Environmental Science and Technology, 32(4):297-336.
LIMA L.M.Q. 1988. Estudo comparativo da recirculação de chorume na aceleração da metanogênese em aterro sanitário. São Carlos. Tese (Doutorado), Escola de Engenharia de São Carlos, Universidade de São Paulo. $2 \mathrm{v}$.

LIMPURB - DEPARTAMENTO DE LIMPEZA URBANA DO MUNICÍPIO DE SÃO PAULO. 2003. Caracterização Gravimétrica e Fisico-química dos Residuos Sólidos Domiciliares do município de São Paulo-2003. 133p.

MARQUES J. F. 2003. Comportamento de ions $\mathrm{Pb}$, Zn e Cu em área impactada por escória, produto da reciclagem de baterias chumboácido. São Paulo. Dissertação (Mestrado), Instituto de Geociências, Universidade de São Paulo. 120p.120p.

POHLAND F.G., HARPER S.R. 198. Critical Review and Summary of Leachate and gas production from landfills. Cincinnati, USEPA, Office of Research and Development. EPA/600/2-86/073.

RAIJ B., QUAGGIO J. A., CANTARELLA H. 1987. Análise quimica do solo para fins de fertilidade. Campinas, Fundação Cargill, 1987 $170 \mathrm{p}$.

SCHALCH V. 1984. Produção e características do chorume em processo de decomposição de lixo urbano. São Carlos. Dissertação (Mestrado), Escola de Engenharia de São Carlos - SHS, Universidade de São Paulo. 103p.

SCHALCH V. 1992. Análise Comparativa do Comportamento de Dois Aterros Sanitários Semelhantes e correlações dos parâmetros do processo de digestão anaeróbia. São Carlos, EESC. Tese de Doutorado. 220p.

TCHOBANOGLOUS G., THEISEN H., VIGIL S. 1993. Integrated Solid Waste Management. Engineering Principles and Management Issues. ............ Nova Iorque, McGraw-Hill. 978p.

Manuscrito A-1607

Revisão aceita em 14 de junho de 2006 
Comportamento geoquímico de ions de metais pesados $(\mathrm{Pb}, \mathrm{Cu}, \mathrm{Cr}$ e $\mathrm{Ni}$ ) em aterros sanitários - simulações de células de lixo em colunas experimentais 